\title{
El combate contra la austeridad en las décadas de los setenta y Ios ochenta: cuando los derechos humanos desaparecieron
}

Contesting Austerity in the 1970s and 1980s: When Human Rights Went Missing

\section{Matthias Goldmann ${ }^{1}$}

\author{
Max Planck Institut/Universidad de Frankfurt, Alemania
}

Revista Derechos en Acción ISSN 2525-1678/ e-ISSN 2525-1686

Año 6/No 18 Verano 2020-2021 (21 diciembre a 20 marzo), 89-129

DOI: https://doi.org/10.24215/25251678e479

Resumen: Si bien el discurso sobre los derechos humanos se volvió fundamental para desafiar la austeridad en el período que siguió a la Gran Crisis Financiera desde una perspectiva histórica, el que los derechos humanos desempeñen este papel es más la excepción que la regla. El discurso en materia de derechos humanos en el contexto de la austeridad inducida por la deuda soberana ha variado mucho con el tiempo. Lejos de mostrar progreso, su historia revela los cambios del paradigma del derecho de los derechos humanos. Las páginas que

\footnotetext{
Profesor adjunto, Goethe University Frankfurt, Alemania. El presente artículo es un fragmento adaptado del capítulo de mi autoría titulado "Contesting Austerity: Genealogies of Human Rights Discourse" e incluido en Nehal Bhuta (ed.), Human Rights in Global Governance: Collected Courses of the Academy of European Law (OUP, 2021, de próxima publicación).

Deseo expresar mi profundo agradecimiento por el análisis crítico al presente trabajo por parte de Nehal Bhuta, Juan Pablo Bohoslavsky, Ingo Venzke, Anuscheh Farahat, Silvia Steininger, Margot Salomon, quienes participaron del curso sobre derechos humanos de junio de 2017 en la Academy of European Law (AEL), también de la Conferencia AEL, celebrada en febrero de 2018 en el European University Institute, y de la conferencia titulada "Contingency in the Course of International Law" de la Universidad de Amsterdam en junio de 2018. Mi agradecimiento también a Hannah Kull y Seoyoung Shin por su asistencia en la inverstigación y a Natalia Barry por la traducción del artículo al español.
} 
siguen hacen foco en uno de esos cambios, ocurrido en la transición entre las décadas de los setenta y ochenta. En la década de los setenta, los Estados recientemente independizados invocaban los derechos humanos en especial para afirmar su soberanía y alejar la interferencia internacional. El paradigma estructural sobre derechos humanos desapareció abruptamente de los debates sobre austeridad en la década de los ochenta, cuando la crisis de deuda soberana golpeó al Sur Global y creó la necesidad de asistencias multilaterales para obtener liquidez. Frente a la presión de reconsiderar el impacto social de los programas de ajuste estructural que promovía, el Fondo Monetario Internacional desplazó los términos del debate y en lugar de hablar de "necesidades humanas", un término relacionado con los derechos humanos, pasó a hablar de "capital humano". En consecuencia, en el momento en que los derechos humanos adquirían el estatus de "última utopía", dejaron de tener relevancia para la austeridad. Por lo tanto, que el discurso sobre los derechos humanos promueva o no los objetivos sociales dependerá del contexto y del momento histórico. El artículo culmina con una propuesta de paradigma político del derecho de los derechos humanos que refleja estas perspectivas.

Abstract: While human rights discourse became fundamental for challenging austerity in the aftermath of the Great Financial Crisis, in historical perspective, such a role of human rights represents the exception rather than the rule. Human rights discourse in the context of sovereign debt-induced austerity has varied enormously over time. Far from reflecting progress, its history reveals changing paradigms of human rights law. This chapter focuses on one of these paradigm shifts occurring at the turn from the 1970s to the 1980s. In the 1970s, newly independent states invoked human rights mostly to assert their sovereignty and avert international interference. This structural human rights paradigm abruptly disappeared from austerity debates in the 1980s, when the sovereign debt crisis hit the Global South, creating a need for multilateral liquidity assistance. Faced with pressure to reconsider the social impact of structural adjustment programmes, the International Monetary Fund shifted the terms of the debate from 'human needs', a human rights-related term, to 'human capital'. Consequently, at the time when human rights rose to the status of the 'last utopia', they ceased 
to have relevance for austerity. Hence, whether human rights discourse promotes social ends depends on the particular context and time. The chapter ends by proposing a political paradigm of human rights law reflecting this insight.

\section{Introducción. Deuda, austeridad y discurso sobre derechos humanos}

El surgimiento de la soberanía de los Estados en los albores de la modernidad, dio origen también a las crisis de deuda soberana. ${ }^{2} \mathrm{Su}$ resolución por lo general ha implicado privaciones para la población del Estado deudor, debido a los ajustes en la política fiscal y económica, medidas conocidas como "austeridad". En los días que siguieron a la Gran Crisis Financiera de 2008, con frecuencia estas privaciones se abordaron desde una perspectiva de derechos humanos. ${ }^{3}$ Como se analizará a continuación, desde una perspectiva histórica, este papel para los derechos humanos en materia de austeridad representa más la excepción que la regla. El discurso sobre derechos humanos en contextos de medidas de austeridad inducidas por deudas soberanas ha variado enormemente con el tiempo. Lejos de mostrar un progreso, la historia de este discurso revela que van cambiando los paradigmas sobre el derecho en materia de derechos humanos. La comprensión de los derechos humanos queda supeditada a la posición y el contexto de quienes participan de este discurso en un ámbito, tiempo y lugar determinados. De este modo, no hay un entendimiento único y, entonces, tampoco una única trayectoria histórica para los derechos humanos. Por el contrario, lo más cercano a una historia exhaustiva sobre

\footnotetext{
2 Para un análisis de las economías que entraron en cesación de pagos (o default) en los primeros años de la modernidad, consultar: Carmen M. Reinhart y Kenneth S. Rogoff, This Time Is Different: Eight Centuries of Financial Folly (Princeton University Press, 2009), 86-87.

3 Para consultar algunos de estos enfoques: Aoife Nolan (ed.) Economic and Social Rights after the Global Financial Crisis (CUP, 2014).
} 
derechos humanos que puede obtenerse es el trazado de un mapa de alternancias entre los distintos paradigmas discursivos en la materia.

Para hacer el seguimiento de estos cambios, el artículo sitúa el discurso sobre los derechos humanos en el contexto de austeridad, comprendido dentro de la lucha más amplia entre "lo económico" y "lo social" en la sociedad. ${ }^{4}$ En un contexto de crisis originada por deuda soberana, se entiende "lo económico" como el interés de los acreedores por maximizar su rédito. Inversamente, "lo social" representa el interés del Estado deudor y su ciudadanía por evitar la austeridad. Es evidente que ambos conceptos representan tipologías ideales. Una crisis de deuda en concreto siempre reflejará una mezcla particular de las infinitas variedades en que encontramos en la realidad estos tipos ideales. Sin embargo, considero que la simplificación inherente a esta dicotomía se justifica, ya que ofrece una orientación discursiva útil.

Como se analizará, la alineación de los derechos humanos con "lo social" ha mostrado altibajos desde siempre. Más bien, el papel de los derechos humanos en el contexto de las crisis de deuda soberana revela ciertas contingencias del discurso sobre los derechos humanos, y es posible desglosarlo en dos ejes de evolución discursiva que difieren y a la vez se intersectan. El primero de ellos traza un mapa de la relación dinámica entre el discurso sobre los derechos humanos y otros conceptos que articulan la preocupación por "lo social", entre ellos, las políticas económicas heterodoxas. El segundo eje hace un seguimiento de la compleja relación existente entre los derechos humanos y los diferentes ideales redistributivos. Los derechos humanos, al igual que sus hermanos constitucionales, los derechos fundamentales, no son aliados naturales de una visión igualitaria de la sociedad ni de cualquier idea de redistribución en particular.

4 Esta distinción se basa en Karl Polanyi, The Great Transformation: The Political and Economic Origins of our Time (Beacon Press, 1944), capítulo 2. 
En cambio, como demostrara Samuel Moyn magistralmente, los derechos humanos oscilan entre la idea de suficiencia - caracterizada por un énfasis en la igualdad de estatus-, los derechos económicos necesarios para proteger contra la interferencia gubernamental y ciertas garantías mínimas de protección social, sumadas a una comprensión más igualitaria con base en una visión de igualdad material relativa, que a menudo implica la intervención del gobierno para concretar bienestar y prosperidad para todas y todos. ${ }^{5}$

La historia de los derechos humanos en contextos de austeridad merece un tratamiento más extenso del que permiten estas páginas. ${ }^{6}$ Nuestro artículo se limita a las décadas de los setenta y los ochenta, por ser un período de interés particular, caracterizado por un cambio de paradigma crucial en cuanto al papel desempeñado por los derechos humanos en estos contextos. En la década de los setenta, cuando las Instituciones Financieras Internacionales (IFI) comenzaron a sentar las bases de los préstamos soberanos y las condicionalidades tal como los conocemos hoy, los derechos humanos tenían un papel muy diferente al que desempeñarían luego de la crisis de 2008. Los Estados recientemente independizados invocaban los derechos humanos más que nada para hacer valer su soberanía, articular sus preocupaciones por encima de la estructura económica internacional y alejar la interferencia internacional, y no tanto para promover políticas sociales específicas en contextos de ajuste estructural. A esto lo llamo yo "el paradigma estructural del discurso sobre los derechos humanos". Según este paradigma, las condiciones impuestas sobre los Estados deudores durante períodos de agobio financiero no despertaban una

5 Samuel Moyn, Not Enough: Human Rights in an Unequal World (Harvard University Press, 2018), 3-4. Para la lectura de una defensa enfática del suficientarianismo: Liam Shields, Just Enough: Sufficiency as a Demand of Justice, (Edinburgh University Press, 2016).

6 Para un estudio detallado ver Goldmann, "Contesting Austerity: Genealogies of Human Rights Discourse" en Nehal Bhuta (ed.), Human Rights in: Global Governance Collected Courses of the Academy of European Law (OUP, 2021, de próxima publicación). 
crítica explícita desde una perspectiva de derechos humanos. Aun así, la Conferencia de las Naciones Unidas sobre Comercio y Desarrollo (UNCTAD, por su sigla en inglés) enfatizó la autodeterminación de los Estados deudores, vista como condición previa para el cumplimiento de los derechos humanos. Es más, la noción de necesidades (humanas) básicas articuló la preocupación sobre los efectos sociales de la austeridad. Si bien este concepto desbordaba ambigüedad por donde se lo viese, había quienes lo entendían como posible vía hacia la materialidad de una sociedad más igualitaria. Para corroborar su posición, alinearon el enfoque de las necesidades (humanas) básicas con el deber de los Estados de implementar los derechos humanos.

El paradigma estructural de los derechos humanos desapareció de pronto de los debates sobre austeridad en la década 1980, cuando la crisis de deuda soberana golpeó al Sur Global. Al tiempo que se incrementaron las demandas por una reconsideración del impacto social de los programas de ajuste estructural, el Fondo Monetario Internacional (FMI) cambió los términos del debate en forma decisiva y dejó de hablar de necesidades humanas para pasar a hablar de capital humano, lo cual afianzó una perspectiva utilitaria que consideraba las políticas de ajuste estructural puramente desde la perspectiva de cómo contribuyen al crecimiento. En consecuencia, los derechos humanos se elevaron al nivel de principios globales constitucionales de base, incluso llegaron a adquirir el estatus de "última utopía", ${ }^{7}$ y al mismo tiempo, no tenían prácticamente impacto en la percepción de la austeridad en esa época. El antiguo paradigma estructural del discurso sobre los derechos humanos dio lugar a un nuevo paradigma liberal sobre ellos que sería difundido desde los organismos internacionales más para disciplinar a los gobiernos que para promover la igualdad. Este paradigma prevaleció hasta fines de siglo.

7 Samuel Moyn, The Last Utopia, (Harvard University Press, 2010). 
Tal como lo muestro en otro lugar, ${ }^{8}$ la crítica de la austeridad basada en un paradigma nuevo y transformador del derecho de los derechos humanos no surgió en la sociedad civil sino hasta la década los noventa. Su impacto sobre la práctica de la austeridad fue escaso hasta que "la guerra contra el terrorismo" influyó en la visión de que las organizaciones internacionales están constreñidas por los derechos humanos.

Por lo tanto, es lógico inferir que el discurso de los derechos humanos no evolucionó estrictamente en paralelo con la propagación de las políticas económicas liberales tales como la austeridad. El surgimiento de la austeridad en un principio fue en complemento a los derechos económicos y sociales como perspectiva de relevancia. Las transformaciones de la economía y de las organizaciones internacionales pueden requerir de cambios en el discurso sobre derechos humanos, que no deben darse por sentado. En el caso que aquí se presenta, no fue sino por algunos acontecimientos fortuitos de otros ámbitos que se restauró el discurso sobre derechos económicos y sociales como medio para combatir la austeridad, aunque el éxito fue limitado. ${ }^{9}$ Aun así, no significa que deba descartase por completo el discurso sobre los derechos humanos. Su (corta) genealogía, tal como se la despliega aquí, ilustra su alto nivel de contingencia inherente como discurso. ${ }^{10} \mathrm{El}$ hecho de que con él se persiga o no la igualdad y los fines sociales es principalmente una cuestión de contexto y momento histórico particulares. El presente artículo culmina con el esbozo de un paradigma político en materia de discurso sobre derechos humanos, que genere el

8 Goldmann, “Contesting Austerity" (núm. 5).

9 Al respecto, acordamos con el análisis de Samuel Moyn en: "A Powerless Companion: Human Rights in the Age of Neoliberalism", en: 77 Law and Contemporary Problems, 2015, 147-169.

10 En referencia a las diferentes genealogías del discurso sobre los derechos humanos: Stefan-Ludwig Hoffmann, "Einführung: Zur Genealogie der Menschenrechte”, en: StefanLudwig Hoffmann (ed.), Moralpolitik Geschichte der Menschenrechte im 20 Jahrhundert, (Wallstein, 2010) 1- 26. 
potencial para que este discurso pueda combatir la austeridad y consolidar una mayor igualdad.

\section{La década de los setenta: una crítica basada en los derechos humanos al alcance de la mano}

La década de los setenta, un período sacudido por las crisis, marcó un punto de inflexión en las políticas relativas a las deudas y la austeridad. El declive de la asistencia oficial para el desarrollo por parte de los países industrializados fue compensado por el Sur Global mediante la expansión masiva de sus préstamos comerciales estimulada, entre otros factores, por el exceso de liquidez de los bancos de operatoria internacional, gracias a las ganancias provenientes del sector petrolífero (o "petrodólares") de los Estados de la OPEP (Organización de Países Exportadores de Petróleo). Con el estancamiento del progreso en materia de crecimiento y desarrollo y los problemas de la deuda que amenazaban, surgió la pregunta de si el FMI no debería expandir su estrecha mirada hacia temas "macro", y tratar las cuestiones del desarrollo con un enfoque más amplio. En 1971, la entidad comenzó a asesorar sobre deuda externa, sobre techos de deuda y otros temas, en el marco de los artículos VIII y XIV de los informes de sus consultas. ${ }^{11}$ Esto iba en línea con los intereses de los prestamistas, que deseaban evitar entremezclar cualquier aporte brindado para el desarrollo con temas vinculados a deuda soberana. ${ }^{12}$ En 1974, el FMI estableció el Servicio Ampliado de Deuda, una nueva funcionalidad de préstamo que proporcionaba financiamiento de largo plazo para superar crisis de deuda. Las condicionalidades contemplaban,

\footnotetext{
11 Jérôme Sgard, "How the IMF Did It. Sovereign Debt Restructuring Between 1970 and 1989", 1 Capital Markets Law Journal, 2016, vol. 11, 107, 103- 125.

12 Minutas de las reuniones del Directorio Ejecutivo 71/33 y 71/34 of. 21; y Documento del FMI SM/71/80 del 23 de abril de 1971; cf. Sundhya Pahuja, “Technologies of Empire: IMF Conditionality and the Reinscription of the North/South Divide", 4 Leiden Journal of International Law, 2000, vol. 13, 749-813, 766.
} 
entre otros instrumentos, los medidores de desempeño, que superaban ampliamente los anteriores objetivos de desempeño. La enmienda al artículo IV del Convenio Constitutivo a inicios de ese mismo año brindó el fundamento legal para que estas condicionalidades fuesen más estrictas. ${ }^{13}$ Su carácter estructural aumentó considerablemente el impacto en las políticas internas.

\section{Trasfondo: el estatismo del bienestar social del período de entre guerras y de posguerra}

Desde la posguerra hasta bien entrada la década de los años setenta, las condicionalidades y la austeridad que conlleva casi no vieron una crítica articulada en términos de derechos humanos, si bien crecía cada vez más la influencia sobre las políticas económicas en los Estados deudores. Recién hacia fines de esa década se hizo posible una crítica con base en los derechos humanos.

Varios factores dan cuenta de este desarrollo. Por un lado, a pesar de que los derechos sociales están incluidos en la Declaración Universal de los Derechos Humanos (DUDH) de 1948, el discurso sobre los derechos económicos, sociales y culturales (los derechos ESC) apenas si logró surgir en las economías industrializadas durante los "Treinta Gloriosos", el período de crecimiento desde mediados de 1940 hasta casi la década de 1960. La nueva historiografía de los derechos humanos ha explorado con cierto detalle las razones para este silencio. ${ }^{14}$ En particular, la inexistencia de un discurso sobre los derechos ESC no tenía nada que ver con el progreso lineal del derecho de los derechos humanos,

13 UNCTAD, Informe of la Junta de Comercio y Desarrollo sobre la primera parte de su decimoquinta sesión en el Palais des Nations, Ginebra (5 al 16 de agosto de 1975) A/10015/ Rev.1 (1976) párrs. 161-63; Pahuja (núm. 11) 769; Axel Dreher y Roland Vaubel, "The Causes and Consequences of IMF Conditionality", 3 Emerging Markets Finance and Trade, 2004, vol. 40, 32, 26-54.

14 Para mayor referencia, ver Joseph R Slaughter, “Hijacking Human Rights: Neoliberalism, the New Historiography, and the End of the Third World", Human Rights Quarterly, 2018, vol. 40, 741, 735-775. 
una narrativa común y autoadulatoria según la cual los derechos liberales clásicos encontraban un camino por el que luego les seguirían los derechos ESC, que se desarrollarían en un segundo paso. En cambio, pareciera que estos últimos entraron en el vocabulario legal y político del siglo veinte en esencia ya desde el período entreguerras. La decadencia del constitucionalismo burgués del siglo diecinueve y el cambio hacia la democracia de masas en los países industrializados en la primera mitad del siglo veinte, por sí mismos trajeron el reconocimiento constitucional explícito de la preocupación por las cuestiones sociales. Los ejemplos paradigmáticos clásicos son la Constitución Mexicana de 1917 y la Constitución de Weimar de 1919, a las que podemos añadir la Constitución Española de 1931, las Cuatro Libertades de Roosevelt de 1941, o la Constitución Italiana de 1948. ${ }^{15}$ Estas cartas fundamentales no solo articulaban la preocupación por lo social en términos de derechos, sino que con frecuencia adoptaban la forma de disposiciones programáticas que pondrían en marcha procesos societarios y políticos para construir el Estado benefactor y equilibrar los intereses divergentes de diferentes sectores de la sociedad. ${ }^{16}$ Si bien la adjudicación de derechos constitucionales (contra los gobiernos, no contra legislaturas) en algunos casos se remonta hasta este período, ${ }^{17}$ la defensa de los derechos ESC frente a la legislatura no formó parte de las prioridades de esta agenda constitucional, ya que en el mencionado período, dado el conservadurismo predominante del poder judicial en varios lugares, se confiaba más en los parlamentos que en las cortes judiciales.

Después de la Segunda Guerra Mundial, el encuadre de la cuestión social se mantuvo prácticamente igual en las distintas

\footnotetext{
15 Agustín J. Menéndez y Matthias Goldmann, "Weimar Moments: Transformations of the Democratic, Social, and Open State of Law", 2020, (en el archivo del autor).

16 Michael Stolleis, "Die Soziale Programmatik der Weimarer Reichsverfassung", en: Horst Dreier y Christian Waldhoff (eds.), Das Wagnis der Demokratie Eine Anatomie der Weimarer Reichsverfassung, (CH Beck, 2018), 195; Roberto Gargarella, Latin American Constitutionalism, 1810-2010: The Engine Room of the Constitution, (OUP, 2013), $101 \mathrm{ff}$.

17 Horst Dreier, “Grundrechtsrepublik Weimar", en: Dreier y Waldhoff (eds.), (núm. 15), 175.
} 
democracias occidentales, aunque la urgencia que la Guerra Fría otorgó a la cuestión, requirió de una apuesta seria en la implementación del Estado benefactor. ${ }^{18}$ Este Estado formaba parte de un proyecto mayor que abogaba por el establecimiento de un orden económico internacional que incluyera al capitalismo como parte integral, a fin de evitar un retorno a la Gran Depresión y la guerra. Nunca más debía volver a permitirse que se materializaran los riesgos surgidos de los intereses económicos sin coordinación ni control. ${ }^{19} \mathrm{Al}$ interior de las economías locales, este período coincidió con el surgimiento abrupto del Estado benefactor. El cuidado de la salud, la mejora de las condiciones laborales y la expansión de la educación secundaria y terciaria son signos visibles del entrelazado profundo entre lo económico y lo social en este período. La curva de Phillips dominaba las políticas del mercado laboral y conducía a políticas macroeconómicas que perseguían un equilibrio entre el desempleo y la inflación. ${ }^{20}$ Este contexto explica por qué los derechos ESC ganaron significatividad limitada como tales en los países industrializados aun después de la adopción de la DUDH. ${ }^{21}$ La protección de los derechos sociales era una tarea de los sistemas de bienestar nacionales. Si se considera el contexto de creación de la DUDH y, en particular, la influencia del constitucionalismo latinoamericano, ${ }^{22}$ es necesario entender dicha Declaración como el establecimiento de un programa al interior de los Estados benefactores, y no como un compendio

18 Para su análisis en Europa, ver: Poul F Kjaer, “The Transnational Constitution of Europe's Social Market Economies: A Question of Constitutional Imbalances?", 57 JCMS: Journal of Common Market Studies, 2019, vol. 57, 143, $147 f f$.

19 John Gerard Ruggie, "International Regimes, Transactions, and Change: Embedded Liberalism in the Postwar Economic Order", 36 International Organization, 1982, 379.

20 Cf. Paul A. Samuelson y Robert M. Solow, "Analytical Aspects of Anti-Inflation Policy", 2 The American Economic Review, 1960, vol. 50, 177.

21 Moyn (núm. 4) 57 ff; Samuel Moyn, "The Universal Declaration of Human Rights of 1948 in the History of Cosmopolitanism", 40 Critical Inquiry, 2014, 365.

22 Mary Ann Glendon, "The Forgotten Crucible: The Latin American Influence on the Universal Human Rights Idea", 16 Harvard Human Rights Journal, 2003, 27. 
de derechos sociales individuales exigibles judicialmente. ${ }^{23}$ Los derechos ESC eran más bien un sinónimo para un concepto nuevo de Estado, un Estado que defendía la democracia de masas y ponía en primer lugar el bienestar de la población.

La dimensión transnacional del bienestar social se formulaba en un lenguaje sobre desarrollo análogo y respiraba el aire de las teorías de la modernización, mas no tanto del discurso sobre derechos. ${ }^{24}$ El desarrollo se convirtió en el medio elegido para superar las asimetrías económicas globales mientras que, de considerar los derechos ESC como prerrogativas, se hubieran originado preguntas más apremiantes sobre la redistribución. Hasta los Estados gobernados por los líderes más autocráticos podían participar en el desarrollo, lo cual permitía que las democracias desarrolladas cooperaran con ellos bajo la premisa de asistirles hasta "madurar" y convertirse en democracias hechas y derechas. Además, el discurso sobre los derechos ESC hubiera dejado al descubierto las fallas de las potencias coloniales. ${ }^{25}$ La mayoría de los análisis académicos pasaron por alto el hecho de que la asimetría del orden económico internacional iba en detrimento del plan de construir un Estado benefactor al interior de cada país, a excepción de Gunnar Myrdal, quien convocó a la coordinación internacional del bienestar social. ${ }^{26}$ Pero hasta Myrdal, en sus ideas profundamente igualitarias, se sustentaba más en una idea de Estado y de moral social que en los derechos como

\footnotetext{
23 Moyn (núm. 4), 55. Como enfatiza Moyn, una publicación de la UNESCO de 1948 muestra el grado alto de escepticismo sobre el futuro de los derechos humanos, ver Mark Goodale, Letters to the Contrary, (Stanford University Press, 2018).

24 Cf. Reinhart Kößler, “Development. Analytical Value and Ideological Baggage of an Elusive Term", en: Uwe H. Bittlingmayer, et al. (eds.), Education and Development in Afghanistan: Challenges and Prospects, (Transcripción, 2019), 48.

25 Jessica Whyte, The Morals of the Market: Human Rights and the Rise of Neoliberalism, (Verso Books, 2019), 120.

26 Para el Ilamamiento a la coordinación internacional del planeamiento en pos del bienestar, ver: Gunnar Myrdal, An International Economy: Problems and Prospects, (Harper \& Brothers, 1956), 51 ff; cf. Moyn (núm. 4), 104 ff.
} 
prerrogativas individuales. ${ }^{27}$ El Estado benefactor debía remediar el sufrimiento causado por la Gran Depresión y la Gran Guerra que le siguió. ${ }^{28}$

De hecho, había quienes consideraban que los derechos eran una variable demasiado individualista para asegurar un cambio de la sociedad como conjunto. Esta postura se refleja en la definición de "investigaciones para la paz" de Johan Galtung, en 1969, quien defendía una noción amplia de paz que contemplaba la justicia social y consideraba a la inanición como forma de "violencia", ya sea estructural o personal. ${ }^{29}$ En un comentario revelador Galtung concede que el estándar de base para la justicia social puede encontrarse en los acuerdos internacionales sobre derechos humanos. Sin embargo, el autor se rehúsa a usar la noción de derechos humanos porque considera que la noción, en el mejor de los casos, consagra prerrogativas personales, en lugar de abordar las causas estructurales que conducen a las desigualdades en la distribución. Los derechos ESC no desafiarían las disparidades de poder a las que responde la distribución desigual. ${ }^{30}$

\section{Surgimiento de un doble paradigma estructural sobre los derechos humanos en la década de los setenta}

El foco puesto en el Estado benefactor por parte de la cooperación en pos del desarrollo de posguerra empezó a disgregarse en la década de los setenta a partir de la comprensión de que la receta del desarrollo a través del crecimiento entraba en

27 Gunnar Myrdal, Beyond the Welfare State: Economic Planning and its International Implications, (Yale University Press, 1960), 95, 277-79. En realidad, solo menciona los derechos en una oportunidad en la página 277, casi al final de la obra y de una manera general; y al pasar, en referencia al derecho a la vida, la libertad y la búsqueda de la felicidad, como parte de la esencia de la cultura del bienestar.

28 Moyn (núm. 4), 48.

29 Johan Galtung, "Violence, Peace, and Peace Research", 3 Journal of Peace Research, 1969, vol. 6, 167-191, 171.

30 Ibídem, 181. 
un impasse. A pesar del crecimiento económico, imperaban el desempleo y la desigualdad. ${ }^{31}$ La crisis de deuda en crecimiento y las cada vez más arduas medidas de austeridad que conllevaba dieron lugar a dos discursos diferentes y, a la vez, relacionados en las organizaciones internacionales que buscaban desafiar la austeridad y replantear la relación entre lo económico y lo social durante las crisis de deuda: la discusión sobre la deuda por parte de la UNCTAD y el enfoque basado en las necesidades (humanas) básicas. Si bien ambos discursos están plagados de ambivalencia en cuanto al papel de los derechos humanos en las políticas económicas, cada uno refleja, en cierta medida, un paradigma nuevo sobre los derechos humanos que difiere mucho de la mirada de Galtung, pues enfatiza su significatividad estructural y remite a ellos para desafiar la austeridad.

El primero de estos discursos surgió del llamado a un Nuevo Orden Económico Internacional (NOEI), una iniciativa derivada de la crítica heterodoxa y estructuralista del orden económico de posguerra prevaleciente, en especial, en Latinoamérica. Ante la percepción de los riesgos que implicaba para los países en desarrollo la liberalización del comercio, Raúl Prebisch, el primer Secretario General de la UNCTAD, defendió ciertas medidas selectivas de proteccionismo que permitieran el desarrollo industrial y la diversificación, con vistas a la sustitución de las importaciones y la redistribución de los beneficios del desarrollo. ${ }^{32}$ Estos esfuerzos culminaron en la propuesta del NOEI; un desafío influyente desde lo intelectual a la hegemonía económica de los países industrializados. ${ }^{33}$

31 Richard Jolly, "The World Employment Conference: The Enthronement of Basic Needs", Development Policy Review, 1976, vol. A9, 31-44; D. John Shaw, World Food Security: A History since 1945, (Springer, 2007), 223.

32 Nora Lustig, "From Structuralism to Neostructuralism: The Search for a Heterodox Paradigm", en: Patricio Meller (ed.), The Latin American Development Debate: Neostructuralism, Neomonetarism, and Adjustment Processes, (Westview Press, 1991).

33 Moyn (núm. 4), $113 \mathrm{ff}$; Quinn Slobodian, Globalists: The End of Empire and the Birth of Neoliberalism, (Harvard University Press, 2018), 219 ff. 
La propuesta dio lugar a una nueva mirada sobre la austeridad en el Sur Global. En la década de los sesenta se había dado mucha atención a la pregunta sobre si los Estados recientemente independizados heredarían la deuda en que incurrieran las potencias coloniales para beneficio de su territorio, y en qué circunstancias dichos Estados podrían descartar esas deudas por su origen detestable u odioso. ${ }^{34}$ Hacia 1970, en el contexto de endeudamiento creciente y de la iniciativa del NOEI, el Sur Global desplazó su foco de atención en pos de un mejoramiento de las prácticas de reestructuración de deuda internacional para reducir la necesidad de austeridad y la desesperación a la que conduce, militar a favor del alivio de la carga de la deuda. Una serie de resoluciones buscaron ubicar ese deseo en la agenda internacional. La segunda UNCTAD en 1968 enfatizó las limitaciones de los marcos ad hoc para reestructurar de deuda. ${ }^{35} \mathrm{La}$ Conferencia Norte-Sur sobre la perspectiva del NOEI, celebrada en París en 1974, dio origen, en el marco de la UNCTAD, al Grupo ad boc de Expertos en Problemas Relacionados con la Deuda Externa de los Países en Desarrollo. Por primera vez desde la guerra un cuerpo internacional elaboraba una serie de recomendaciones para un enmarque institucional efectivo y de base amplia para las reestructuraciones de deuda y que, aún hasta hoy, son pertinentes en su mayoría. ${ }^{36}$ Algunos años

\footnotetext{
34 Commisión de Derecho Internacional, "First Report on Succession of States in Respect of Rights and Duties Resulting from Sources other than Treaties", por el relator especial Mohammed Bedjaoui, UN Doc A/CN.4/204 (1968). Para un estudio de los casos, ver: Jeff King, The Doctrine of Odious Debt in International Law: A Restatement (CUP, 2016), 79-80; y también: Marc Frey, "A Revolutionary Process? Decolonization and International Law", en: Norbert Frei y Annette Weinke (eds.), Toward a New Moral World Order? Menschenrechtspolitik und Völkerrecht seit 1945, (Wallstein, 2013), 122.

35 UNCTAD, Beyond Conventional Wisdom in Development Policy. An Intellectual History of UNCTAD 1964-2004, (United Nations, 2004), 33.

36 UNCTAD, Report of the Trade and Development Board, (10 de marzo - 2 de octubre de 1975), UN Doc A /10015/Rev. 1, ANEXO A, “Document Submitted by the Group of Seventy-Seven and Romania on Proposed Additional Policy Measures for Incorporation into the International Development Strategy for the Second United Nations Development Decade", párr. 22.
} 
después Tanzania propuso que esta comisión internacional contemplara en su competencia las cuestiones de equidad social al momento de decidir sobre una reestructuración de deuda ${ }^{37}$ Este proceso culminó con la resolución 222 (XXI) que, en su anexo, estipula los "elementos detallados para las operaciones futuras relacionadas con los problemas de deuda de los países en desarrollo interesados". ${ }^{38}$ Este documento constituye un compromiso. Deja abierta la posibilidad de un alivio de deuda para los Estados deudores mientras que institucionaliza de una manera insuficiente un mecanismo formal de reestructuración de deuda. ${ }^{39}$

Si bien la resolución no menciona los derechos humanos, el contexto del NOEI y su relación con ellos deja entrever que estos esfuerzos podrían efectivamente entenderse, en el marco de la UNCTAD, como una perspectiva de derechos humanos genuina solo que con otro nombre ${ }_{\diamond}$ con un enfoque orientado a salvaguardar los derechos humanos en un sentido estructuralista, mediante el reajuste del equilibrio de la relación entre lo económico y lo social a nivel global. Esto se desprende del papel que desempeñan los derechos humanos en la iniciativa del NOEI, aunque esta relación no estuviera libre de ambigüedades.

Por un lado, no era evidente para los defensores del NOEI que un lenguaje de derechos, como sería la implementación de esta agenda - una variante de la economía de desarrollo inspirada en la de Keynes-, lo primero que requería era un Estado fuerte y no prerrogativas individuales. ${ }^{40}$ Más aun, los debates

\footnotetext{
37 Sgard (núm. 10), 108.

38 UNCTAD, Junta de Comercio y Desarrollo, Resolución 222 (XXI) del 27 de septiembre de 1980.

39 Enrique Cosio-Pascal, "The Emerging of a Multilateral Forum for Debt Restructuring: The Paris Club", Documento de Debate de la UNCTAD 192 (noviembre de 2008), 11.

40 Upendra Baxi, “The New International Economic Order, Basic Needs and Rights: Notes Towards Development of the Right to Development", 23 Indian Journal of International Law 225, (1983); Moyn (núm. 4), 117.
} 
del NOEI eran un reflejo de ciertas tensiones generales entre descolonización y derechos humanos. ${ }^{41}$ No todos los países que apoyaban el NOEI demostraban gran respeto por la democracia y los derechos humanos internamente, e invocarlos los ponía en un lugar de controversia. Tal fue el caso del escepticismo expresado hacia los derechos civiles y políticos en la Conferencia de Teherán sobre Derechos Humanos de $1968 .{ }^{42}$ Otros estudios del período también reconocían el potencial neoimperialista inherente al discurso sobre derechos humanos, aunque estas preocupaciones no se expresaron por completo hasta el surgimiento, en las décadas que siguieron, del discurso de Occidente sobre derechos humanos. ${ }^{43}$ Es posible que fueran estas las razones por las cuales los documentos internacionales que establecían el NOEI casi no mencionan los derechos humanos. De hecho, la Declaración del NOEI contiene solo una referencia a la dignidad humana, si bien pone énfasis en la soberanía y la construcción de Estados benefactores a nivel interno. ${ }^{44} \mathrm{La}$ Carta de Derechos y Obligaciones Económicas de los Estados que sucedió al NOEI al menos menciona que los Estados tienen el deber de cumplir con las normas internacionales en materia de derechos humanos. ${ }^{45}$

Por otro lado, la lucha por la independencia en el Sur Global, que proporcionó el contexto para la idea del NOEI, se alineaba

\footnotetext{
41 Jan Eckel, Die Ambivalenz des Guten: Menschenrechte in der Internationalen Politik seit den 1940ern, (Vandenhoeck \& Ruprecht, 2014), 260 ff.

42 Roland Burke, Decolonization and the Evolution of International Human Rights, (University of Pennsylvania Press, 2010), $99 \mathrm{ff}$.

43 Johan Galtung, "The New International Economic Order and the Basic Needs Approach", 4 Alternatives, 1979, Vol. 4, 455, 462-476; Makau Wa Mutua, "The Ideology of Human Rights", 36 Virginia Journal of International Law, 1996, 589-657.

44 Declaration on the Establishment of a New International Economic Order (Declaración para el Establecimiento de un Nuevo Orden Económico Internacional), UNGA Res. 3201 (S-VI) (1 ${ }^{\circ}$ de mayo de1974), UN Doc. A/RES/S-6/3201.

45 Charter of Economic Rights and Duties of States (Carta de Derechos Económicos y Deberes de los Estados), UNGA Res. 3281 (XXIX) (12 de diciembre de 1974), UN Doc $\mathrm{A} / \mathrm{RES} / 29 / 3281$, capítulo 1, literalmente, apartado " $k$ ".
} 
estrechamente con un entendimiento colectivo y estructural de los derechos humanos. En consecuencia, la igualdad y la independencia soberanas eran consideradas requisitos indispensables para el cumplimiento de los derechos humanos por vía del desarrollo económico. ${ }^{46}$ Este encuadre de los derechos humanos se refleja en el primer artículo de cada uno de los dos Pactos Internacionales. De modo similar, la Proclamación de Teherán de 1968 pone énfasis en la liberación nacional, el antirracismo y el desarrollo económico como desafíos clave para el cumplimiento de los derechos humanos. ${ }^{47} \mathrm{~A}$ la luz de esto, hay quienes llegan incluso a declarar que la conexión entre derechos humanos, autodeterminación y desarrollo se había vuelto tan fuerte que el Sur Global monopolizaba el discurso sobre derechos humanos y hacía que las economías industrializadas se vieran poco atraídas a participar de él; y esto no cambió hasta el redescubrimiento de los derechos humanos en la década de los setenta. ${ }^{48}$

Esta última línea de pensamiento revela la existencia de un paradigma estructural en materia de derechos humanos,

46 RP Anand, "Sovereign Equality of States in International Law II", 4 International Studies, 1966, vol. 8, 406, 386-421; Christian Reus-Smit, "Human Rights and the Social Construction of Sovereignty", 4 Review of International Studies, 2001, vol. 27, 519-538; Bradley R. Simpson, "Self-Determination, Human Rights, and the End of Empire in the 1970s", 2 Humanity, 2013,vol. 4, 239-260; Moyn (núm. 4), 104, 111-12; Slaughter (núm. 13); Janne Mende, "Are Human Rights Western-And Why Does it Matter? A Perspective from International Political Theory", Journal of International Political Theory (de próxima aparición) (2019); Burke (núm. 41), 37. Este vínculo entre igualdad soberana y desarrollo recuerda la idea kantiana de libertad formal e igualdad, de la cual Kant creía que podría traer la justicia social, ver Frederick Rauscher, "Kant's Social and Political Philosophy", en: Edward N. Zalta (ed.), The Stanford Encyclopedia of Philosophy Archive (Spring, edición 2017), disponible en inglés en: https://plato.stanford. edu/archives/spr2017/entries/kant-social-political/ [consultado el 1 de junio de 2020].

47 Naciones Unidas, Acta Final de la Conferencia Internacional sobre los Derechos Humanos (22 de abril - 13 de mayo de 1968), UN Doc. A/CONF.32/41, capítulo II, “Proclamación de Teherán".

48 Jan Eckel, "Symbolische Macht. Antikolonialismus und Menschenrechte in den Vereinten Nationen", en: Frei y Weinke (eds.) (núm. 33), 134, 142-3. Para el renacimiento del discurso sobre los derechos humanos en Occidente, ver: Moyn (núm. 6), 120 ff. 
y era un paradigma que defendía el reclamo de un NOEI. Se impuso en medio de los debates en torno al surgimiento del derecho al desarrollo y se constituyó como derecho colectivo de expresión del deseo de la autodeterminación nacional en materia económica y de un orden económico internacional justo, más que de prerrogativas individuales. ${ }^{49}$ La práctica de las Naciones Unidas en materia de derechos humanos en la década de los sesenta, período de incubación del derecho al desarrollo, refleja este entendimiento de los derechos humanos y su alineación estrecha con el NOEI. Llama la atención que, en su resolución 32/130 de 1977, la Asamblea General esboce un conjunto exhaustivo de "distintos criterios y medios posibles dentro del sistema de las Naciones Unidas para mejorar el goce efectivo de los derechos humanos y las libertades fundamentales”. Allí se estipula que las cuestiones referentes a los derechos humanos requieren de una perspectiva global y se desplaza el foco de atención: se aleja de una perspectiva de prerrogativas individuales y se acerca a una visión del sufrimiento colectivo caracterizado por la dominación de Occidente, que incluye al apartheid, el colonialismo, las amenazas a la soberanía nacional y la soberanía sobre los recursos naturales. La resolución prosigue a declarar que concretar el NOEI es esencial para promover los derechos humanos. ${ }^{50}$ En este sentido, la resolución 222 (XXI) de la UNCTAD sobre los problemas vinculados con la deuda en los países en desarrollo - una de las creaciones preciadas del NOEI- es una de las piezas dentro del mosaico que es la lucha más amplia por la independencia económica, entendida como una lucha por los derechos humanos.

El segundo discurso que desafió a la austeridad se conoció como el enfoque basado en las necesidades (humanas) básicas.

49 Cf. Declaración sobre el Derecho al Desarrollo, UNGA Res. 41/128 (4 de diciembre de 1986) UN Doc. A/RES/41/128.

50 UNGA Res. 32/130 (16 de diciembre de 1977), párrs. 1 (d) y (f); ver: Baxi (núm. 39), 227; Julia Dehm, "Highlighting Inequalities in the Histories of Human Rights: Contestations over Justice, Needs and Rights in the 1970s", 31 Leiden Journal of International Law 871, 2018, 882ff. 
Comenzó a desplegarse casi en todas las organizaciones internacionales a cargo de temas de desarrollo desde aproximadamente la década de los setenta. La carrera del concepto recibió un impulso decisivo por parte de la Organización Internacional del Trabajo (OIT) que, en ese momento, enfrentaba la comprensión de que el crecimiento por sí solo no conduciría al desarrollo equitativo, la paz y la estabilidad del mundo en desarrollo. Para poner el tema de la redistribución sobre la mesa, el organismo desplazó su foco de atención hacia las necesidades (humanas) básicas. Los pormenores en torno de este debate y su enfoque central son demasiados para detallarse en el presente análisis. ${ }^{51}$ Basta con afirmar que nunca se terminó de resolver por completo si estas necesidades básicas implicaban un concepto "de trazo grueso" e igualitario del bienestar, o si apuntaban tan solo a un mínimo de suficiencia.

Por otra parte, la Conferencia Mundial Tripartita sobre el Empleo, la Distribución de los Ingresos, el Progreso Social y la División Internacional del Trabajo; celebrada en 1976, ya desde el título sugiere que se propondría niveles de distribución más ambiciosos. En consecuencia, su Programa de Acción extendía, de manera explícita, la noción de necesidades básicas más allá de lo necesario para la supervivencia y estipulaba que un empleo digno, íntegro y justo debía procurar un ingreso, pero también asegurar la autovalidación y la dignidad. ${ }^{52}$ Abogaba por un enfoque participativo basado en múltiples influencias, entre otras, los enfoques heterodoxos de las políticas económicas de China y Tanzania. ${ }^{53}$ En consecuencia, el concepto de

\footnotetext{
51 Ver: Reginald Herbold Green, "Basic Human Needs: Concept or Slogan, Synthesis or Smokescreen?", 4 The IDS Bulletin, 1978, vol. 9, 7-11; Assefa Bequele y David H. Freedman, "Employment and Basic Needs: An Overview", 3 International Labour Review, 1979, vol. 118, 315-329; Dehm (núm. 49), 875.

52 Conferencia Mundial del Empleo, Declaración de Principios y Programa de Acción (5 de julio de 1976) UN Doc. E/5857 párrs. 4-5.

53 Green (núm. 50), 8; ver también: Jean Mouly, “Employment: A Concept in Need of Renovation", 116 International Labour Review, 1977, vol. 116, 1-7; Bequele y Freedman (núm. 48), 318.
} 
necesidades humanas básicas se asoció tanto a pisos mínimos como a techos de ingreso. ${ }^{54}$

En contraposición, el enfoque del Banco Mundial basado en las necesidades básicas, promovido por el presidente McNamara, se planteó objetivos menos ambiciosos pues se concentraba en la pobreza y, por lo tanto, en los más necesitados. ${ }^{55} \mathrm{El}$ énfasis en la eficiencia y la supuesta falta de respeto inherente al enfoque de las necesidades básicas por la autodeterminación produjo críticas de parte de los representantes del Tercer Mundo, ${ }^{56}$ sin embargo, mantuvo su influencia a través de la proeza institucional del Banco Mundial.

Dada la ambigüedad intrínseca del enfoque de las necesidades (humanas) básicas, hay quienes trazaron una conexión con los derechos humanos, a fin de inclinar la balanza hacia un significado "de trazo grueso" y de igualdad. Un desplazamiento de tales características era casi esperable. La Proclamación de Teherán de 1968 había instaurado cierta costumbre por encuadrar las cuestiones de desarrollo en un lenguaje de derechos humanos. ${ }^{57}$ El texto de la Declaración de Principios de la Conferencia Mundial del Empleo de 1976, con su marcada aspiración a la igualdad, aprovechó el impulso e hizo referencia explícita a la DUDH y, puntualmente, al derecho al trabajo. De hecho, esta Declaración motivó a Phillip Alston a resaltar las similitudes y diferencias entre las necesidades (humanas) básicas y los derechos humanos, y así fundir dos tendencias discursivas en pos de los objetivos igualitarios que tenía en mente. ${ }^{58}$ De manera

\footnotetext{
54 Green (núm. 50), 10.

55 Moyn (núm. 4), 131, 190. Para un trasfondo de los debates del Banco Mundial, ver Dehm (núm. 49), 879.

56 Galtung (núm. 42), 461 ff.

57 Naciones Unidas, Acta Final de la Conferencia Internacional sobre los Derechos Humanos (22 de abril - 13 de mayo de 1968) UN Doc. A/CONF. 32/41, capítulo II, “Procamación de Teherán", párrs. 12 y 13.

58 Philip Alston, "Human Rights and Basic Needs: A Critical Assessment", Human Rights Journal / Revue des Droits de I'Homme, 1979, vol. 12, 21, 19-67.
} 
similar, Upendra Baxi argumentó que el enfoque basado en las necesidades (humanas) básicas reflejaba un concepto igualitario de los derechos ESC. ${ }^{59}$ Por lo tanto, la asociación de los derechos humanos con las necesidades (humanas) básicas representaba una estrategia discursiva para reivindicar lo social frente a lo económico en el continuo repensar de la economía del desarrollo. Una vez más, la comprensión de los derechos humanos que emerge en este contexto expresa un paradigma estructural. Más que garantizar prerrogativas individuales o la autodeterminación, los derechos humanos están destinados a facilitar un desarrollo de calidad, que contemple justo y pleno empleo, y no la mera suficiencia.

Entonces, hacia fines de la década de los setenta, tanto el debate de la UNCTAD sobre deuda como el enfoque de las necesidades (humanas) básicas (los dos discursos pertinentes para enmarcar la austeridad a nivel internacional en esta década) estaban alineados en varios aspectos y se fundamentaban en un paradigma estructural sobre los derechos humanos que les daba un papel que desempeñar en la relación entre lo económico y lo social (eje 1). Cada uno de estos discursos mostraba cierta afinidad, aunque limitada, hacia formas más igualitarias de redistribución (eje 2). El debate del NOEI se sustentaba en una idea poco desarrollada sobre los derechos humanos y solo se concentraba en el impacto agregado del orden internacional sobre la situación económica de Estados y grupos. El enfoque basado en las necesidades (humanas) básicas quedó atrapado en medio de las disputas entre igualdad y suficiencia. Sin embargo, a pesar de estas ambigüedades, en retrospectiva, parecía posible que una comprensión estructuralista de los derechos humanos se convirtiera, de un modo u otro, en un estándar altamente relevante para la gobernanza de las crisis de deuda soberana y la austeridad. ${ }^{60}$

\footnotetext{
59 Baxi (núm. 39), 228-29.

60 Cf. Baxi (núm. 39), 233.
} 


\section{La década de los ochenta: el pasaje de las necesidades humanas al capital humano}

El potencial paralelo entre gobernanza de crisis de deuda soberana y discurso sobre derechos humanos no se materializó en la década siguiente a los setenta, si bien fue una década signada por una ola gigante de austeridad extendida por todo el Sur Global. Esta oleada le seguía los pasos a una reforma de las condicionalidades en 1979, que restringía el uso de criterios de desempeño. ${ }^{61}$ La desbordante crisis de deuda del mundo en vías de desarrollo, que rebasó su límite por primera vez en 1982 con la entrada en cesación de pagos de México, rápidamente hizo virar el discurso sobre austeridad en dirección contraria y condujo a un aumento continuo de los criterios de desempeño, lo cual impuso medidas de austeridad más duras sobre los Estados deudores. Este resurgimiento de la austeridad era injustificado y contraproducente. La crisis de deuda fue en especial el resultado de eventos globales mayúsculos, como el aumento de las tasas de interés en los Estados Unidos y la caída de los precios de las commodities durante la transición de los países desarrollados de una economía industrial a una economía de servicios. Sin embargo, la enorme expansión de las actividades prestamistas del FMI creó restricciones de financiamiento por parte del organismo, lo cual lo llevó a imponer medidas de austeridad aún más exigentes para asegurar que sus reembolsos llegaran en los tiempos estipulados. En respuesta a la crisis, el FMI abrió dos ventanas concesionales, la Facilidad de Ajuste Estructural y la Facilidad Mejorada de Ajuste Estructural, iniciadas respectivamente en 1986 y $1987 .{ }^{62}$ Y había otra razón para estas iniciativas, una razón ideológica. El Plan Baker, adoptado en 1985, defendía la creencia de que los Estados deudores

61 Decisión del FMI Núm. 6056-(79/38) (2 de marzo de 1979), párr. 4; Erik Denters, Law and Policy of IMF Conditionality, (Springer, 1996), 96.

62 Dreher y Vaubel (núm. 12), 37; James M. Boughton, Silent Revolution: The International Monetary Fund 1979-1989 (International Monetary Fund, 2001), 644 ff. 
deben superar las crisis de deuda con una actitud que podría resumirse como "apretar los dientes y poner manos a la obra". Unos ajustes despiadados, semejantes al estado de shock, y una orientación de mercado radical se asegurarían de que comenzara a hacer efecto pronto el crecimiento y de que se derramara a todos los escalones de la jerarquía social. ${ }^{63}$ El Plan Baker se implementó gracias a una coalición de apoyo compuesta por gobiernos de países desarrollados, bancos internacionales y autoridades del FMI del más alto nivel. ${ }^{64}$ Este plan hizo que la resistencia del Sur Global fuera infructuosa. ${ }^{65}$ En términos legales, los lineamientos sobre las condicionalidades daban al FMI suficiente margen interpretativo para este revés tan profundo de la reforma de 1979, y a esto se suma que la distinción entre criterios macroeconómicos y microeconómicos es todo, menos clara, pues varias medidas producen efectos de ambos tipos. ${ }^{66}$

Como resultado, el manejo de las crisis de deuda se convirtió en un esfuerzo mayor internacionalmente coordinado y estrictamente regulado, de niveles de austeridad significativos, es decir, de políticas fiscales contradictorias. ${ }^{67}$ No solo aumentó la cantidad de condicionalidades, sino que además cambiaron en calidad. Una incorporación digna de mencionar fue la de las metas estructurales indicativas (structural benchmarks). ${ }^{68}$ Con ellas se prescriben reformas estructurales de supuesto efecto a largo plazo, por ejemplo, un replanteo integral de la administración pública de las finanzas. Si bien implicaban un costo alto para la soberanía, se esperaba que estas metas enviaran

\footnotetext{
63 Boughton (núm. 61), 417; Naomi Klein, The Shock Doctrine: The Rise of Disaster Capitalism (Macmillan, 2007), 155ff.

64 Para una reconstrucción meticulosa, ver: Alexander E. Kentikelenis y Sarah Babb, “The Making of Neoliberal Globalization: Norm Substitution and the Politics of Clandestine Institutional Change", 6 American Journal of Sociology, 2019, vol. 124, 1720-1762.

65 Reinhart y Rogoff (núm. 1) 91-92; Pahuja (núm. 11) 782 ff.

66 Denters (núm. 60), 111.

67 Cf. Mark Blyth, Austerity: The History of a Dangerous Idea, (OUP, 2013), $161 \mathrm{ff}$.

68 Dreher y Vaubel (núm. 12), 32; Boughton (núm. 61), 417.
} 
una fuerte señal a los acreedores y restauraran la confianza crediticia del país. ${ }^{69} \mathrm{El}$ precio de este flamante ajuste estructural consistió en el enorme impacto sobre los derechos ESC, efectivo principalmente en el recorte de subsidios y servicios públicos, con su respectiva y simultánea liberalización y privatización.

Con este trasfondo de debates, a lo largo de la década de los setenta, podría haberse esperado que el alcance de las críticas basadas en los derechos (humanos) básicos adoptara la forma, al menos en parte, de un discurso maduro sobre derechos humanos. De hecho, una de las críticas más poderosas - a la que el FMI por fin reaccionó, en tanto organismo a cargo de aprobar los programas de ajuste- fue propiciada por otras organizaciones internacionales mediante un lenguaje de necesidades (humanas) básicas. En ese sentido, fue clave la actividad del Banco Mundial y del Fondo de las Naciones Unidas para la Infancia (UNICEF). ${ }^{70}$ El caso de UNICEF es, en particular, interesante. Posiblemente estuvo entre las primeras organizaciones en notar los efectos de las formas nuevas de austeridad en el aumento en las tasas de desnutrición infantil, las dificultades que afligían a la situación social de las mujeres, así como en otros grupos vulnerables de la sociedad. ${ }^{71}$ Un informe de 1983 recomendaba una mezcla de medidas diferentes. Algunas de ellas apuntaban a un mejor aseguramiento de las necesidades básicas primordiales mediante la propuesta de estrategias simples que utilizaban escasos recursos de maneras más eficientes, en un enfoque compatible con la idea de suficiencia. ${ }^{72}$ Otras perseguían metas más ambiciosas y relacionaban la dura experiencia de la niñez con demás injusticias globales mayores,

\footnotetext{
69 Wolfgang Streeck, "The Rise of the European Consolidation State", Max-Planck-Institut für Gesellschaftsforschung, Documento de Debate 15/1, (2015), 12

70 Si bien los informes de quienes se participaron del lado de UNICEF exageran el papel desempeñado, el historiador oficial del FMI reconoce dichas influencias externas, ver Boughton (núm. 61), 694-95.

71 Maggie Black, Children First: The Story of UNICEF, Past and Present, (OUP, 1996), 158.

72 UNICEF, The State of the World's Children 1984, (OUP, 1983), $5 \mathrm{ff}$.
} 
como los problemas de la educación de las mujeres, la desigualdad en el ingreso y la escisión norte-sur del orden global. ${ }^{73} \mathrm{El}$ informe de gran influencia titulado Ajuste con rostro humano, publicado por UNICEF en 1987, mostraba una mezcla similar de suficiencia e igualdad. Al igual que otros informes de la entidad, evitaba el término "derechos humanos" pero, en concreto, todo su contenido versaba sobre ellos. ${ }^{74} \mathrm{El}$ informe comienza con la - ahora célebre- pregunta retórica del expresidente de Tanzania, Julius Nyerere: “¿Debemos matar de hambre a nuestros niños para pagar deudas?". ${ }^{75}$ A continuación, el informe recomienda extender los tiempos del ajuste y pasar de un foco extremadamente cortoplacista a períodos de recuperación de mediano y largo plazo, lo cual requiere volúmenes financieros mayores y alivios de deuda. Si bien reconoce la necesidad de proteger a los sectores vulnerables, considera medidas que van más allá de la suficiencia, por ejemplo, la idea de un "ajuste expansionista" que evite la deflación. Se podría decir, entonces, que combina el deseo de mayor eficiencia, aseguramiento de estándares mínimos, y la conciencia de una necesidad de mayor redistribución general.

La respuesta del FMI a estas propuestas en un principio fue brusca. ${ }^{76}$ A diferencia del Banco Mundial, el FMI hasta ese momento no había internalizado el enfoque de las necesidades (humanas) básicas. Todavía se entendía a sí misma como una organización de mandato macroeconómico y no de economía de desarrollo. Desde esta perspectiva quedaba abierta la

\footnotetext{
73 Ibídem, 23, $57 \mathrm{ff}$ y 67.

74 UNICEF, Adjustment with a Human Face (Ajuste con rostro humano), publicado en: UNICEF, The State of the World's Children 1987, (OUP, 1986). En 1977, UNICEF adoptó una política sobre los servicios básicos que suena minimalista, ver: Alston (núm. 57), 24. No obstante, en virtud de los diferentes temas que trataba, esta política no abordaba cuestiones de mercado laboral y distribución del ingreso.

75 UNICEF (núm. 73), 95.

76 Ver el análisis de Richard Jolly, "Adjustment with a Human Face: A UNICEF Record and Perspective on the 1980s", 12 World Development, 1991, Vol. 19, 1807-1821.
} 
pregunta de si el ajuste era la causa o la cura del problema. De hecho, el organismo había estudiado el impacto distributivo del ajuste desde la década de los setenta y no había establecido si el ajuste empeoraba los efectos distributivos de una crisis de deuda en comparación con escenarios que no presentaran programas de ajuste. ${ }^{77}$

Sin embargo, en el período que siguió UNICEF y las instituciones Bretton Woods comenzaron, a pedido de estas últimas, un diálogo sobre las políticas referidas a la cuestión. ${ }^{78}$ Este diálogo sobre políticas produjo un resultado desconcertante: el director ejecutivo del FMI, Jacques de Larosière, en un discurso notable y citado con frecuencia, reconoció de hecho la urgencia de asegurar las necesidades humanas básicas, pero dio un giro inesperado a la noción:

Los programas de ajuste no pueden ser efectivos a menos que comanden el apoyo de los gobiernos y la opinión pública. No obstante, este apoyo será cada vez más difícil de sostener si los ajustes perduran y no se nota su amortización en términos de crecimiento, más aún si van deteriorándose las condiciones humanas. Del mismo modo, es difícil visualizar cómo pueda lograrse una vía externa viable si hay grandes segmentos de la mano de obra que carecen de capacidades vocacionales - o peor aún, de los estándares más básicos de nutrición y saludpara producir bienes que resulten competitivos en los mercados mundiales. El capital humano, después de todo, es el factor de producción más importante tanto en los países en vías de desarrollo como en los industrializados. ${ }^{79}$

Con tan solo un párrafo, De Larosière dejó de hablar de "condiciones humanas" (que podrían considerarse equivalentes a las

\footnotetext{
77 Ibídem, 1811; Boughton (núm.61), 696.

78 Informe del Directorio Ejecutivo de UNICEF (24 de febrero de 1987) E/ICEF/1987/2; Black (núm. 70), 158.

79 Declaraciones de Larosière ante el Consejo Económico y Social de la ONU (4 de julio de 1986), citado en Jolly (núm. 75), 1816.
} 
"necesidades humanas") y pasó a hablar de "capital humano". Dejó perdidos en el camino la orientación estructural y el componente igualitario, antes asociados con el enfoque de las necesidades (humanas) básicas, tal como lo había presentado UNICEF; y así, las necesidades (humanas) básicas se volvieron muy difíciles de concretar en el contexto de liberalización del mercado, como elabora posteriormente el discurso. ${ }^{80}$ En consecuencia, a la vez que se omite por completo la desigualdad en el ingreso, se cultiva la imagen del Estado derrochador. Y no reconforta demasiado el hecho de reconocer que el recorte en las inversiones puede ser perjudicial, ya que deja en duda si se refiere a la inversión privada o pública. En otras palabras, este discurso brindado a unos meses del lanzamiento del Plan Baker y de la Facilidad de Ajuste Estructural, pone en la misma línea el enfoque de las necesidades (humanas) básicas con aquello que últimamente se ha dado en llamar el Consenso de Washington. ${ }^{81}$ El cambio fue sutil pero claro. El concepto de necesidades (humanas) básicas, que hubiera podido ser un marcador de posición para una idea igualitaria sobre derechos humanos, fue inclinado hacia la suficiencia y privado de su potencial en pos de la igualdad. Lo económico prevaleció sobre lo social.

Este cambio conceptual fue paradigmático para los debates sobre la austeridad, que tuvieron lugar en la década de los ochenta. Fue testigo del casi completo abandono del paradigma estructural de los derechos humanos que venía de los debates sobre austeridad de la década anterior. El vacío no fue llenado de inmediato ni con otro discurso ni con un paradigma sobre los derechos humanos. Para explicar la ausencia de voces que los nombraran en el coro de críticas a la austeridad es útil considerar el contexto más amplio en el que tenían lugar estos debates. Había una serie de razones por las cuales no era una elección

\footnotetext{
80 Ver Ibídem.

81 John Williamson, "Democracy and the Washington consensus'", 8 World Development, 1993, vol. 21, 1329-1336.
} 
obvia, ni atractiva, para UNICEF o cualquier otro actor elegir formular su escepticismo ante la reciente ola de austeridad en el lenguaje de los derechos humanos.

En primer lugar, no hay demasiada evidencia respecto a que la falta de críticas a la austeridad, basadas en perspectivas de derechos humanos, fuesen resultado del extensamente descripto redescubrimiento de los derechos humanos en Occidente hacia fines de la década de los setenta, en medio del declive de la Unión Soviética, el surgimiento del neoliberalismo y las amenazas terroristas; y su relación con la aparición de un nuevo paradigma liberal antiguo de los derechos humanos, considerados principalmente como prerrogativas individuales y negativas. ${ }^{82} \mathrm{Si}$ bien no hay razones para dudar respecto a qué se debió el surgimiento de ese paradigma, parece improbable que fuera eso lo que llevó a UNICEF a abstenerse de emitir una crítica a la austeridad desde una perspectiva de derechos humanos a mediados de la década de los ochenta. En aquel momento, el cambio hacia un paradigma liberal de los derechos humanos estaba todavía en proceso y los entendimientos alternativos de los derechos humanos todavía encontraban eco en las organizaciones internacionales. Las Naciones Unidas estaban en medio del surgimiento de una tercera generación de derechos humanos. ${ }^{83}$ Un elemento importante en ese proceso era el derecho al desarrollo, aprobado en $1986 .{ }^{84}$ En ese sentido, fueron años en que UNICEF participó activamente de la redacción de la Convención sobre los Derechos del Niño, un acuerdo desbordante de derechos humanos de segunda y

82 Eckel (núm. 40), 343 ff; Moyn (núm. 6), 120ff; Moyn (núm. 4), 70 ff; para un estudio del cambio neoliberal en las normas sobre derechos humanos, ver: Upendra Baxi, The Future of Human Rights, (OUP, 2007); B. S. Chimni, "International Institutions Today: An Imperial Global State in the Making", 1 European Journal of International Law, 2004, vol. 15, 11, 1-37.

83 Philip Alston, "A Third Generation of Solidarity Rights: Progressive Development or Obfuscation of International Human Rights Law?", 3 Netherlands International Law Review, 1982, vol. 29, 307-322; Slaughter (núm. 13), 753.

84 Declaración sobre el Derecho al Desarrollo (núm. 48). 
tercera generación y, al menos a primera vista, con un alcance que iba mucho más allá de la suficiencia. ${ }^{85}$

Hay otra razón que parece más plausible: simplemente no se había establecido la práctica de criticar las operaciones de los organismos internacionales por sus antecedentes en relación con los derechos humanos. De hecho, los derechos humanos internacionales surgieron en el período de posguerra como una protección contra los Estados nacionales y sus gobiernos y no contra los organismos internacionales. En la década de los años sesenta, los movimientos de liberación invocaban los derechos humanos para reclamar su igualdad de soberanía respecto de otros Estados, y no de las organizaciones internacionales. Como ya se demostró, el enfoque basado en las necesidades básicas y el NOEI entendían las organizaciones internacionales como instrumentos para la promoción y el cumplimiento de los derechos humanos. Una cosa es debatir cómo deben las IFI promover los derechos humanos y otra muy distinta es declarar que sus operaciones los amenazan. En línea general, la idea de los organismos internacionales como amenaza a los derechos humanos no se imponía como sucede en la actualidad. Esto aparece como resultado del legado del funcionalismo, la teoría de mediados del siglo XX que había representado a las organizaciones internacionales como agentes de paz mediante la burocracia racional. ${ }^{86}$ Por lo tanto, el acto de imaginar la

\footnotetext{
85 Decumentación interna de la Oficina del Alto Comisionado de las Naciones Unidas para Ios Derechos Humanos, "Legislative History on the Convention on the Rights of the Child", Save the Children's Resource Centre, (2007). Disponible en inglés en: https://resourcecentre. savethechildren.net/library/legislative-history-convention-rights-child-volume-1 [consultado el 1 de junio de 2020].

86 Cf. David Mitrany, "The Functional Approach to World Organization", 3 International Affairs, 1948, vol. 24, 350-363. Para un análisis sobre el surgimiento del paradigma funcionalista, ver: Jan Klabbers, "The Emergence of Functionalism in International Institutional Law: Colonial Inspirations", 3 European Journal of International Law, 2014, vol. 25, 645-675. Para un estudio de los efectos duraderos, ver: Jens Steffek, "Max Weber, Modernity and the Project of International Organization", 4 Cambridge Review of International Affairs, 2016, vol. 29, 1502-1519. Para un ejemplo fascinante sobre la visión funcionalista de las organizaciones
} 
austeridad impuesta por el FMI como un problema de derechos humanos puede parecer mucho más evidente para nosotros de lo que le resultaba a UNICEF y sus contemporáneos en aquel momento. Pudo haber contribuido el hecho de que el mandato del FMI, tal como se lo enunciaba en la doctrina oficial, no se extendía a consideraciones "no económicas". ${ }^{87}$ Los límites del mandato eran la barrera de contención para los criterios de desempeño estructurales, ${ }^{88}$ y agregar los derechos humanos a la ecuación hubiera puesto potencialmente en juego la posición de quienes deseaban un ejercicio más restrictivo del mandato. En cualquier caso, el FMI reaccionaba a los argumentos económicos mucho mejor que a los no económicos. ${ }^{89}$

Es de esperar que por estas razones existan muy pocas críticas académicas a la austeridad desde una perspectiva de derechos humanos hasta fines de la década de $1980 .{ }^{90}$ En lugar

internacionales, ver: Wolfgang G Friedmann, The Changing Structure of International Law, (Stevens \& Sons, 1964).

87 Joseph Gold, "Conditionality", 31 IMF Pamphlet Series, 1979, 61. De esta manera, Así fue que, en 1978, una comisión parlamentaria supuso sin dudarlo que los derechos de membresía no podían ser restringidos por los derechos humanos; ibídem 62; François Gianviti, Economic, Social, and Cultural Human Rights and the International Monetary Fund, (2001). Para el historial funcionalista de esta mirada: Mac Darrow, Between Light and Shadow: The World Bank, the International Monetary Fund and International Human Rights Law, (Hart Publishing, 2003), 205-06. Para una deconstrucción temprana de esta doctrina, ver: Richard Swedberg, "The Doctrine of Economic Neutrality of the IMF and the World Bank", 4 Journal of Peace Research, 1986, vol. 23, 377-390.

88 Para un estudio de la superposición de la economía y la política, y el subsiguiente deseo del Directorio de limitar los criterios de desempeño a los indicadores macroeconómicos, ver: Gold (núm. 86), 66.

89 Joseph Gold, "Financial Assistance by the International Monetary Fund: Law and Practice", IMF Pamphlet Series Núm. 27, (1979), 14-15; Laurence Boisson de Chazournes, "The Bretton Woods Institutions and Human Rights", en: Wolfgang Benedek, Koen de Feyter, y Fabrizio Marrella (eds.), Economic Globalisation and Human Rights, (CUP, 2007), 210, 214.

90 Para un ejemplo fuera de lo común, ver: Margaret Conklin y Daphne Davidson, "The IMF and Economic and Social Human Rights: A Case Study of Argentina, 1958-1985", 8 Human Rights Quarterly 227, 1986. También ver: James H. Mittelman y Will Donald, “The International Monetary Fund, State Autonomy and Human Rights", 1/2 Africa Today, 1987, vol. 34, 49-68. (Sin embargo, esta última fuente se centra en las violaciones de los derechos civiles y 
de invocar los derechos humanos, la academia y las organizaciones internacionales intercambiaban argumentos económicos y debatían sobre el camino más deseable y eficiente hacia el crecimiento y el desarrollo. ${ }^{91}$ El caso paradigmático es el de una conferencia convocada por la OIT en 1987, que reunía a cantidad de participantes clave en la toma de decisiones. Quienes participaron estuvieron de acuerdo sobre los efectos devastadores de las recientes crisis de deuda en el empleo y las condiciones humanas, pero nadie formuló una crítica a la austeridad en términos de derechos humanos. En cambio, la UNCTAD y una serie de Estados en vías de desarrollo, como Tanzania, recordaron el marco del NOEI al momento de exigir más recursos y una mejor distribución, tanto en la relación entre países como al interior de cada país, ${ }^{92}$ mientras que el FMI y los países occidentales insistieron en ajustes estructurales mediante la liberalización como vía para el crecimiento. Las conclusiones de esa conferencia combinaban un alegato en pos de las necesidades básicas con ciertas concesiones algo generales sobre los procedimientos, que enfatizaban la necesidad de consenso amplio sobre los programas de ajuste en los Estados deudores. ${ }^{93}$ Les esperaba una suerte similar a las iniciativas regionales que habían expresado críticas análogas que refutaban el ensañamiento de las políticas de ajuste neoliberal y que proponían enfoques más heterodoxos. Con el Consenso de Cartagena, los países latinoamericanos más duramente afectados reclamaron financiamiento adicional y alivios de deuda, ${ }^{94}$

políticos cometidos por gobiernos de Estados deudores, mediante la imposición de programas de ajuste en sus poblaciones).

91 OIT, "High Level Meeting on Employment and Structural Adjustment", Documento de la OIT WEP 2-46-04-03, (23-25 de noviembre de 1987).

92 Ibídem, párr. 18.

93 Ibídem, 28 (párr. 1), 30 (párr. 16); ver: Joel M. Ngugi, “Policing Neo-Liberal Reforms: The Rule of Law as an Enabling and Restrictive Discourse", University of Pennsylvania Journal of International Economic Law, 2005, vol. 26, 570, 513.

94 Consenso de Cartagena, en: 205 El Trimestre Económico, 1985, vol. 52, 267-272; ver también: Arturo O'Connell, “La Coordinación de los Deudores Latinoamericanos: El Consenso 
a lo cual los países exportadores de capital respondieron con el Plan Baker. En 1989, la propuesta de la Comisión Económica de la ONU para África, que consistía en un marco de ajuste alternativo para el continente, defendía un enfoque más holístico del ajuste y más a largo plazo, lo cual permitiría un aumento de la producción y la diversificación para las economías regionales. Pero el FMI desestimó la propuesta. ${ }^{95}$

Al final, en ese período, no había prácticamente nadie que tuviera razones suficientes para invocar los derechos humanos en contra de la austeridad. Los gobiernos de los Estados deudores dominados por la crisis con frecuencia quedaban comprometidos, ya que la implementación de la austeridad casi siempre involucraba flagrantes violaciones a los derechos humanos. ${ }^{96}$ El caso de Chile en la década de los setenta había dejado al descubierto el potencial impacto que podían tener las campañas por los derechos humanos en la opinión pública global. ${ }^{97}$ En la vereda opuesta, la oposición política desarrolló un interés por presentarse como los mejores deudores, tanto antes como después de ascender al poder. ${ }^{98}$ Los llamamientos a la cancelación de la deuda fundamentados en su carácter odioso no volvieron a surgir con fuerza plena hasta finales del siglo. ${ }^{99}$

de Cartagena y el Grupo de los Ocho", en: 83 Estudios Internacionales, 1988, vol. 21, 373-385.

95 Comisión Económica de las Naciones Unidas para África, "African Alternative Framework to Structural Adjustment Programmes for Socio-Economic Recovery and Transformation" (1989); el acuerdo común con el FMl que sucedió a este encuentro refleja más desacuerdo que consenso, ver: Jolly (núm. 75), 1817.

96 M Rodwan Abouharb y David L. Cingranelli, "IMF Programs and Human Rights, 19812003", 4 The Review of International Organizations 47, 2008.

97 Eckel (núm. 40), 583 ff; ver también: Horace A. Bartilow, The Debt Dilemma: IMF Negotiations in Jamaica, Grenada and Guyana, (Caribbean, 1997); Jolly (núm. 75), 1816.

98 Cf. Bartilow (núm. 96), 139.

99 Klein (núm. 62), 156 ff. En esta fuente, la autora relata los debates odiosos en los Estados Latinoamericanos que se sucedieron a las autocracias. Sin embargo, fuera de algunas menciones ocasionales, no hay demasiada evidencia de dicho debate en la sociedad civil o el entorno académico antes de mediados de los años noventa. Entre las contadas excepciones se puede considerar a Günter Frankenberg y Rolf Knieper, "Legal Problems of the Overindebtedness of 
Así fue como el conflicto por la austeridad en la década de los años ochenta quedó enmarcado como disputa entre distintos enfoques de las economías en competencia, y los actores poderosos favorecieron la respuesta neoliberal. El poder detentado por quienes controlaban los fondos, por parte del Plan Baker, pudo haber contribuido al éxito irrevocable de su estrategia, pero también el hecho de que el enfoque estructural defendido por los economistas del desarrollo de Latinoamérica de posguerra se había originado precisamente con esta crisis. ${ }^{100} \mathrm{La}$ izquierda política de América Latina y de otras latitudes encontraba difícil formular una respuesta alternativa al creciente torbellino neoliberal. ${ }^{101}$ Y se sumaban más dificultades por el hecho de que los

Developing Countries: The Current Relevance of the Doctrine of Odious Debts", 12 International Journal of the Sociology of Law 415, (1984); Luis Díaz Müller, "El Derecho al Desarrollo y los Derechos Humanos", 4 Revista IIDH5, (1986). Los intercambios vinculados a una deuda odiosa en los años 1980 y comienzos de los 1990 se refieren fundamentalmente a casos antiguos, como los bonos chinos de 1911, por ejemplo: Tamar Lewin, "Legal Claims against China", en: The New York Times (Nueva York, 29 de noviembre de 1983), sección D 2. Las únicas referencias que estimularon un debate enriquecedor sobre el carácter odioso o detestable de las deudas de las dictaduras fueron el uso del concepto en el informe de 1998 de la Comisión de la Verdad y la Reconciliación de Sudáfrica y el alivio de deuda otorgado a Irak después de la guerra de 2003. Ver: Comisión de la Verdad y la Reconciliación de Sudáfrica, 4 Informe Final, 1998, párr. 151; Lee C. Buchheit, G. Mitu Galati y Robert B. Thompson, "The Dilemma of Odious Debts", Duke Law Journal, 2006, vol. 56, 1220, 1201-1262 (para debates anteriores) y 1230 (sobre Irak). El debate en cuestión revisó de manera crítica la deuda en que incurrió la dictadura cívico militar en Argentina, por ejemplo, en: David Harvey, The New Imperialism, (OUP, 2003), 159-60; Eric Toussaint, Your Money or Your Life! (Pluto, 2003), 200 ff; Sabine Michalowski, “Repayment of Sovereign Debts from a Legal Perspective: The Example of Argentina", en: Janet Dine y Andrew Fagan (eds.), Human Rights and Capitalism A Multidisciplinary Perspective on Globalisation, (Elgar, 2006), 303, 309. Para una evaluación más cautelosa, ver: Anna Gelpern, "What Iraq and Argentina Might Learn from Each Other", 6 Chicago Journal of International Law 391, (2005). El debate prosigue hasta hoy. En relación con Chile, ver la reciente publicación de Juan Pablo Bohoslavsky, Karinna Fernández y Sebastián Smart (eds.), Complicidad Económica con la Dictadura Chilena. Un País Desigual a la Fuerza, (LOM Ediciones, 2019).

100 Blyth (núm. 66), 161; Patrice Franko, The Puzzle of Latin American Economic Development (Rowman \& Littlefield, 2018), 70.

101 Jolly (núm. 75), 1817; Barry Carr, “The Mexican Left, the Popular Movements, and the Politics of Austerity 1982-1985". En: Barry Carr y Ricardo Anzaldúa Montoya (eds.), The Mexican Left, the Popular Movements, and the Politics of Austerity. (University of California, 1986), 1; Moyn (núm. 4), 128 ff. 
Estados deudores no se pusieran de acuerdo sobre las políticas económicas y que algunos de ellos hasta se comprometieran con la austeridad. No hay duda de que el Plan Baker citaba con extremo deleite las palabras del presidente mexicano: "La única forma de superar nuestra crisis económica es atacar de raíz los problemas estructurales de nuestra economía para hacerla más eficiente y productiva". ${ }^{102}$ Miradas de este tipo ponían presión sobre países como Ghana, Zambia o Tanzania que deseaban una política económica diferente, ya fuera en las palabras o en los hechos. ${ }^{103}$

No sorprendió entonces que una de las consecuencias de esta crisis de deuda fuera la marginalización de la UNCTAD como foro relevante para tratar los temas referentes a la deuda, al menos en comparación con su posición en la década de los setenta. Si bien siguió monitoreando la situación de la deuda, se evaporó el impulso que habían ganado sus resoluciones anteriores, y el ímpetu decisivo llegó de parte de los gobiernos de Occidente y las IFI.

En conclusión, de los acontecimientos de la década de los ochenta, es posible extraer una nueva perspectiva sobre el hecho de que una cosa es hacer un llamamiento a cambios en el orden económico imperante en nombre de los derechos humanos y otra muy distinta es operacionalizarlos para que constituyan una crítica a los programas de ajuste. El tránsito de un paradigma a otro requiere de un cambio considerable en la función de los derechos humanos. La primera visión se apoya en la soberanía del Estado, la segunda presupone que se defina el papel de los derechos humanos en la gobernanza global. Los

102 El Plan Baker se presenta en: Detlev CHR Dicke (ed.), Foreign Debts in the Present and a New International Economic Order, (University Press Firbourg, 1986), 290. La cita se encuentra en la página 294.

103 Para un estudio sobre la persistencia heterodoxa, ver Jolly (núm. 75), 1817. Para más información sobre Ghana y Zambia, ver John Baloro, "African Responses to the Debt Crisis: the Relevance of Public International Law", (1991), 24. En: Verfassung und Recht in Übersee / Law and Politics in Africa, Asia and Latin America 28. 
derechos humanos prácticamente tuvieron que pasar de bando y esto les llevó tiempo. Por lo tanto, los derechos humanos no hicieron casi nada por prevenir que lo económico prevaleciera sobre lo social en los debates sobre austeridad de la década de los ochenta. El discurso sobre los derechos humanos simplemente no estaba preparado para la globalización neoliberal.

\section{Conclusión: las contingencias del discurso en materia de derechos humanos}

La historia no termina aquí. ${ }^{104}$ La década de los noventa presenció el nacimiento de un paradigma transformador sobre los derechos humanos en cuanto a críticas a la austeridad que respaldaba una comprensión igualitaria de los derechos ESC. Pero aun cuando fue una década que alcanzó niveles hostiles de austeridad, las críticas basadas en los derechos humanos quedaban al margen. El paradigma transformador fue desplazado por un paradigma liberal -y en ese momento, dominante- que veía el derecho de los derechos humanos como estándar internacionalmente garantizado para los gobiernos a nivel interno y que, a su vez, en el mejor de los casos, atribuía a los derechos socioeconómicos el estatus de red de contención frente a la pobreza extrema. Desde mi punto de vista, recién la experiencia del atentado del 11 de septiembre de 2001 y las críticas basadas en los derechos humanos que le sucedieron por parte de las organizaciones internacionales, desembocaron en la penetración de las críticas a la austeridad basadas en los derechos humanos, en medio de las secuelas de la Crisis Financiera Global. Aun cuando los litigios abundaron después de 2010, llevaron a un éxito magro. El paradigma transformador prosiguió su lucha contra el paradigma liberal y los tribunales con frecuencia no consideraban que fuese su tarea proteger la igualdad, incluyendo los privilegios de la clase

104 Para un análisis detallado, ver Goldmann (núm. 5). 
media. ${ }^{105}$ Además, la estructura de múltiples niveles de los programas de ajustes estructurales y su naturaleza de soft law se interponían en el camino del escrutinio judicial. ${ }^{106}$ No obstante, hubo algunos acontecimientos significativos en la práctica de las instituciones internacionales. En la labor de los órganos de derechos humanos de la ONU, el discurso sobre derechos humanos está enraizado ahora más firmemente que nunca como estándar de gran relevancia para la evaluación del ajuste estructural. ${ }^{107}$ Y el FMI reaccionó con una reconsideración de sus políticas sobre el gasto social, con lo cual enfatizó la necesidad de que el crecimiento fuera inclusivo. ${ }^{108}$

¿Cuáles son las lecciones de este relato del derecho sobre derechos humanos? Primero, la historia del discurso sobre los derechos humanos se caracteriza por las luchas entre paradigmas muy diferentes que expresan miradas altamente divergentes sobre el papel de los derechos humanos en pos del equilibrio entre lo económico y lo social (eje 1) y de la redistribución material y la igualdad (eje 2). Estos paradigmas surgen como resultado de la contextualidad histórica particular. No hay una única historia sobre los derechos humanos, sino varias.

En segundo lugar, el discurso sobre los derechos humanos se adapta a paso muy lento. El hecho de que un paradigma

105 Claire Kilpatrick, "Constitutions, Social Rights and Sovereign Debt States in Europe: A Challenging New Area of Constitutional Inquiry", en: Bruno de Witte, Claire Kilpatrick, and Thomas Beukers (eds.), Constitutional Change Through Euro-Crisis Law, (CUP, 2017), 313.

106 Margot E. Salomon, "Of Austerity, Human Rights and International Institutions", en: 4 European Law Journal, 2015, vol. 21, 521-545; Joe Wills y Ben TC Warwick, "Contesting Austerity: The Potential and Pitfalls of Socioeconomic Rights Discourse", en: 23 Indiana Journal of Global Legal Studies, 2016, 629.

107 Algunos ejemplos: Consejo de Derechos Humanos, "Principios rectores relativos a las evaluaciones de los efectos de las reformas económicas en los derechos humanos Informe del Experto Independiente sobre las consecuencias de la deuda externa y las obligaciones financieras internacionales conexas de los Estados para el pleno goce de todos los derechos humanos, sobre todo los derechos económicos, sociales y culturales". (19 de diciembre de 2018) UN Doc. A/HRC/40/57.

108 FMI, "A Strategy for IMF Engagement on Social Spending-Background Papers", Documento normativo del FMI Núm. 19/017 (14 de junio de 2019). 
nuevo gane impulso o no, depende de los intereses de los actores involucrados, las predisposiciones estructurales y la dependencia de patrones establecidos; y también, hasta cierto punto, de la mera coincidencia. Los choques paradigmáticos que se producen pueden redundar en que las críticas basadas en los derechos humanos sean ineficaces. Por lo tanto, deberíamos movernos con cautela al momento de atribuir la persistencia de las IFI a intereses económicos enemigos, promovidos solo por Estados miembros poderosos, frente a las críticas más mordaces basadas en los derechos humanos. Porque también hay un costado conceptual al conflicto. Las críticas siempre se basan en un paradigma particular de derechos humanos y ninguno de ellos ha gozado de aceptación universal. Así podría explicarse por qué la reacción de las IFI era con frecuencia, en cierto punto, una respuesta indirecta de ajuste a sus políticas, sin adoptar, del todo, un lenguaje de derechos humanos.

Esto nos lleva a un tercer punto y a una pregunta. ¿Vale la pena emplear el derecho de los derechos humanos como remedio efectivo contra la austeridad? La respuesta no debe sorprendernos: depende del paradigma particular en materia de derechos humanos que se emplee. En el paradigma político actual los derechos humanos permiten la construcción de consensos en un ámbito dispar de diferentes agentes escépticos ante la austeridad, en el cual se encuentran organizaciones intergubernamentales, organizaciones no gubernamentales, organizaciones transnacionales de muy diferente orientación ideológica, actores locales, gobiernos y hasta organizaciones internacionales. Dado el profundo afianzamiento cultural de la austeridad ${ }^{109}$ tal función no es una victoria menor.

Se relaciona con esto la capacidad del discurso sobre los derechos humanos de aumentar la complejidad de la toma de decisiones: puede desafiar al discurso económico desde argumentos no económicos. Esta capacidad impacta en el punto débil de

109 Blyth (núm. 66). 
las instituciones que potencialmente promueven la austeridad. Como su hábitat natural es el ámbito de la experiencia económica, por ejemplo para el FMI o la "troika" europea, el hecho de confrontarlos con enfoques económicos (heterodoxos) en lugar de argumentos basados en los derechos humanos les permite avanzar sin alterarse en lo más mínimo. Pueden solo ignorarlos, declarar que saben más al respecto y esconder bajo la alfombra el desacuerdo normativo subyacente. Tal fue el destino del NOEI y del tipo de economía intervencionista de desarrollo con que se relacionaba lo propuesto por Prebisch y defendido desde la UNCTAD. Hasta la altísima autoridad de Joseph Stiglitz, quien había criticado las fallas de la creencia ortodoxa durante décadas, al final tuvo que dejar su cargo de economista jefe del Banco Mundial por los desacuerdos del enfoque del Banco en el manejo de las crisis asiática y rusa. ${ }^{110} \mathrm{Si}$ la experiencia no es bienvenida puede ser, simplemente, descartada.

Lo que no puede descartarse son los derechos humanos. Cambian de lugar las discusiones y hacen que dejen de centrarse en el crecimiento y la eficiencia, para pasar a atender otros ejes donde la primacía del crecimiento no es algo obvio ni dado. Aun cuando las Instituciones Bretton Woods lograron reinterpretar los desafíos sociales como cuestiones de desarrollo e implementación efectiva de programas, en particular frente al cambio hacia el capital humano, los derechos humanos en cierta medida desafían su experiencia. La ironía está en que la supuesta neutralidad de estas instituciones, y del FMI en particular, fortalece los derechos humanos en la misma medida en que los silencia. Desde este ángulo, gran parte del debate doctrinario sobre las obligaciones referidas a los derechos humanos por parte del FMI parece irrelevante. Como estrategia discursiva para combatir la austeridad, su éxito se fundamenta en la falacia de que existe

110 Richard W Stephenson, “Outspoken Chief Economist Leaving World Bank”. En: The New York Times, (Nueva York, 25 de noviembre de 1999). Disponible en inglés en: www.nytimes. com/1999/11/25/business/outspoken-chief-economist-leaving-world-bank.html [consultado el 1 de junio de 2020]. 
solo un entendimiento correcto y compartido universalmente de los derechos humanos, y que lo controlan quienes critican al FMI. En el statu quo, el discurso sobre los derechos humanos expone a las instituciones como el FMI a una medida de escrutinio cuyos términos no pueden controlar, en tanto sí pueden controlar los debates sobre el mérito económico de la austeridad. Entonces, precisamente el hecho de no considerarse obligado por los derechos humanos es lo que vuelve al FMI vulnerable al discurso sobre los derechos humanos.

Resta una última pregunta: ¿es posible infundirle igualitarismo a la austeridad mediante el discurso sobre los derechos humanos para cuestionar la suficiencia de manera efectiva? No parece haber acuerdo sobre este punto en la literatura sobre el tema. Samuel Moyn opina que una teoría igualitaria de la distribución socioeconómica sería más exigente que los derechos humanos, ${ }^{111}$ mientras que Paul O`Connell, entre otros, realizó un llamamiento a un nuevo ímpetu de los derechos humanos frente a la austeridad. ${ }^{112}$

Desde mi punto de vista, la consolidación de una mayor igualdad, no solo es posible, sino que merece la pena como intento. Para el éxito, un primer paso necesario es tomarse en serio el paradigma político y desmitificar el carácter apolítico de los derechos humanos y de la supuesta naturaleza política de los derechos sociales. ${ }^{113}$ Este encuadre del discurso sobre los derechos humanos fue el legado del paradigma liberal que sólo contempla las contingencias implícitas en las decisiones en pos de suficiencia y que esconde los enfoques más alternativos e igualitarios que hacen honor a la promesa del cumplimiento progresivo de los derechos socioeconómicos. En cambio, es

\footnotetext{
111 Moyn (núm. 8), 168.

112 Paul O'Connell, “On Reconciling Irreconcilables: Neo-Liberal Globalisation and Human Rights", 7 Human Rights Law Review, (2007), 483.

113 Acerca del mito, ver también Susan Marks, "Four Human Rights Myths", en: David Kinley, Wojciech Sadurski, y Kevin Walton (eds.), Human Rights: Old Problems, New Possibilities. (Edward Elgar Publishing, 2013), 217, 229.
} 
necesario reafirmar el carácter transformador del discurso legal como receptáculo posible para las ideas progresistas que catalizan procesos políticos de desarrollo e integración sociales, más que como medio para codificar los capitales financieros, atrincherar la moralidad o generar una sobredependencia agobiante de las cortes judiciales. Dado que el paradigma transformador sobre los derechos humanos viene con un foco fuerte en los tribunales, ${ }^{114}$ la propuesta del paradigma político requeriría retomar la idea original del constitucionalismo transformador como parte integral de las constituciones del período entreguerras y de posguerra, que veía a la política y a los movimientos sociales al frente de la transformación social ${ }^{115}$ y de hacer avanzar esta idea sobre los derechos humanos en el contexto de marcos institucionales contemporáneos para su protección.

Quienes aún expresen escepticismo hacia el paradigma político deben considerar un último aspecto: abandonarlo no haría más que dar lugar a otro paradigma inminente. Lo único que se lograría es volver a despolitizar el derecho de los derechos humanos, solo que esta vez no al servicio del capital financiero sino de los beneficiarios del paternalismo autoritarito. ${ }^{116}$

\footnotetext{
114 Kilpatrick (núm. 104).

115 Menéndez y Goldmann (núm. 14).

116 Para consultar el manifiesto legal del paternalismo autoritario, ver Adrian Vermeule, "Beyond Originalism" (The Atlantic, 31 de marzo de 2020). Disponible en inglés en: www. theatlantic.com/ideas/archive/2020/03/common-good-constitutionalism/609037/ [consultado en junio de 2020].
} 